Article

\title{
Analytical Modeling of the Temperature Using Uniform Moving Heat Source in Planar Induction Heating Process
}

\author{
Feng $\mathrm{Li}^{1,2, *}$, Jinqiang Ning ${ }^{2}\left(\mathbb{C}\right.$ and Steven $\mathrm{Y}$. Liang ${ }^{2}$ \\ 1 College of Mechanical and Vehicle Engineering, Taiyuan University of Technology, Taiyuan 030024, China \\ 2 George W. Woodruff School of Mechanical Engineering, Georgia Institute of Technology, 801 Ferst Drive, \\ Atlanta, GA 30332-0405, USA; jinqiangning@gatech.edu (J.N.); steven.liang@me.gatech.edu (S.Y.L.) \\ * Correspondence: lifeng02@tyut.edu.cn
}

Received: 6 February 2019; Accepted: 4 April 2019; Published: 6 April 2019

check for updates

\begin{abstract}
The planar induction heating possesses more difficulties in industry application compared with traditional spiral induction coils in mostly heat treatment processes. Numerical approaches are adopted in the power distribution and temperature prediction during the induction heating process, which has a relatively low computational efficiency. In this work, an analytical calculation model of the planar induction heating with magnetic flux concentrator is investigated based on the uniform moving heating source. In this model, the power density in the surface of the workpiece induced by coils is calculated and applied into the analytical model of the temperature calculation using a uniform moving heat source. Planar induction heating tests are conducted under various induction coil parameters and the corresponding temperature evolution is obtained by the infrared imaging device NEC R300W2-NNU and the thermocouples. The final surface temperature prediction is compared to the finite element simulation results and experimental data. The analytical results show a good match with the finite element simulation and the experimental results, and the errors are in reasonable range and acceptable. The analytical model can compute the temperature distribution directly and the computational time is much less than the finite element method. Therefore, the temperature prediction method in this work has the advantage of less experimental and computational complexity, which can extend the analytical modeling methodology in induction heating to a broader application.
\end{abstract}

Keywords: planar induction heating; magnetic flux concentrator; analytical modeling; uniform moving heat source; simulation

\section{Introduction}

Induction heating usually is applied as the main heating means in various heat treatment processes [1,2], for example, induction hardening, tempering, stress relieving. Besides, induction heating technology also can be used to assistant some other industrial processes, such as crack detection, depth determination [3], induction heating-assisted compaction [4], etc. In these traditional induction heating processes, the shapes of the induction coils are mostly spiral, that is, the parts to be heated are cylindrical parts. Since the electromagnetic field distribution inside the spiral coil is relatively uniform, the induction heating has the characteristics of fast heating and high efficiency [2]. However, the coil required for the planar induction heating is significantly different from the traditional spiral coils, in which the magnetic field distribution is difficult to effectively concentrated, the air impedance of the system loop is too large and the heating temperature is not uniform and difficult to control accurately [5-7]. The efficiency of the planar induction heating extensively depends on the effective conversion of the electromagnetic field of the coil and the reasonable matching of the 
induction heating system. As shown in Figure 1, the emergence of special magnetic flux concentrators has effectively increased the efficiency of the planar induction heating, thus expanding the application of this heating process [8-10].

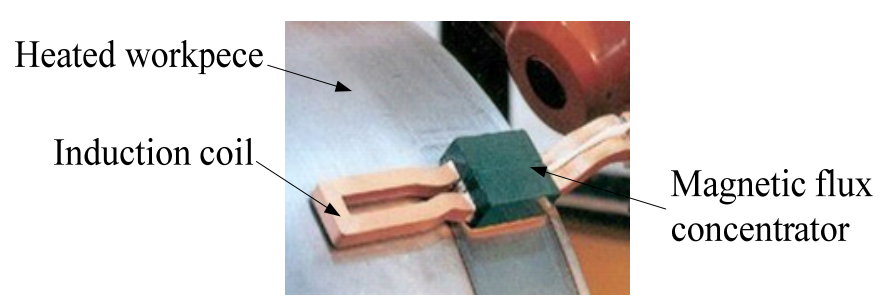

Figure 1. Application of the planar induction heating.

In recent years, in order to apply the induction heating process more effectively, many scholars have conducted more research on induction heating [11-19], including numerical modeling of induction heating process and electromagnetic field conversion mechanism analysis. Numerical approaches are adopted in the power distribution and temperature prediction during induction heating process [11-15]. Barka N. [11] analyzes the machine parameters on the hardness profile heated by induction heating through simulation coupling electromagnetic and heat transfer with finite element methods. Luozzo N.D. [12] uses the finite element method to investigate the heating stage of a bonding process, especially the temperature evolution in the inner and outer surface of the steel tubes. Choi J.K. [13] conducts the study on the induction hardening based on the electromagnetic-thermal finite element simulation, and verifies the hardening depth and hardening pattern. Khazaal M.H. [14] focuses on the modeling and design of the induction coils in a brazing process by finite element method. Li F. $[10,15]$ mainly focus on a planar induction heating process with magnetic flux concentrator, and analyzes the factors influencing the temperature profile and the heating efficiency during the coupled electro-magnetic-thermal field through the finite element simulation and experiments. Numerical simulation based on the finite element method made considerable progress in the induction heating process. However, due to the complexity of the reality physic model, it is inevitable to require the large computational cost, which will cause inconvenience and difficulty in the temperature prediction of the whole computational filed during the induction heating.

In addition, analytical approaches are also adapted in the research of various fields. The analytical approaches have less computational time than finite element simulation and thus have a relatively high efficiency $[16,17]$. Computational efficiency also depends on the mathematical complexity of the analytical model. Ning J. uses the analytical model to investigate the temperature and the cutting force during the orthogonal cutting process. The analytical modeling of induction heating is rather different from other manufacturing processes. Some researchers also try to introduce analytical modeling to analyze the induction heating process. Jankowski T.A. [18] presents a multiple-scale perturbation method to solve the multi-physics mathematical model of induction heating process in a cylindrical coil. Streblau M. [19] uses a multi-physics mathematical model to analysis the electromagnetic and thermal fields in axial symmetric inductor system. However, the computational efficiency and the precision in the analytical modeling of the induction heating process should be made more progress, especially in the planar inductor system.

In order to verify the temperature profile, experimental methods usually are used during the finite element modeling and analytical modeling. Generally, the temperature evolution was acquired by the infrared imaging device and the thermocouples $[10,13]$. Although the temperature can be investigated directly by experimental measurement, the measuring errors still are inevitable, due to the different methods of thermocouples embedding, the accuracy of the measurement equipment and other uncontrollable factors.

In this work, authors present an analytical model to calculate the temperature profile during the planar induction heating process with magnetic flux concentrator. The moving heating source 
in the analytical model is treated as a uniform moving heat source. The power density of induced eddy current in the heated workpiece can be obtained based on Maxwell equations, which govern the general induction heating. Then the transient temperature evolution will be calculated using the mathematical equations defined as a rectangle moving heating source with the uniform power. The final temperature obtained from the analytical computation is compared with the finite element simulation and the experimental results. Compared with the finite element simulation methods and the former experimental results, the proposed analytical model of temperature calculation in this work has the advantage of less mathematical complexity, experimental complexity and high computational efficiency.

\section{Methodology and Validation}

\subsection{Analytical Modeling of the Temperature Calculation}

The schematic flow of the variables in temperature evolution is shown in Figure 2. The induction heating process is governed by the Maxwell equations, as shown in Equations (1)-(4) [2]. I and $f$ are the current intensity and frequency of the induction coil. The induced power density of eddy current in the surface $q_{v}$ is calculated by the Maxwell equations and then the power $P_{L}$ applied as input parameters in the temperature calculation can be obtained. The calculation model of the temperature is used as a uniform moving heating source, which will be illustrated as follow.

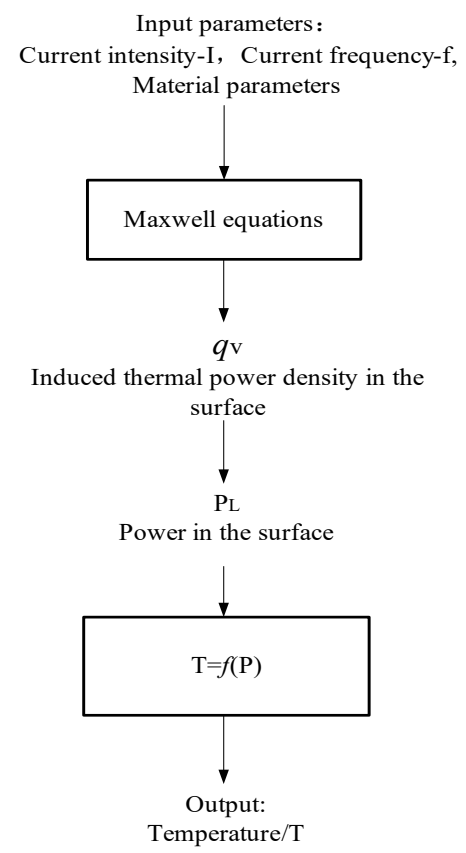

Figure 2. Schematic flow of the variables in temperature evolution.

$$
\begin{gathered}
\nabla \times H\left(I, f, \mu_{M F C}\right)=J+\frac{\partial D}{\partial t}, \\
\nabla \times E=-\frac{\partial B}{\partial t} \\
\nabla \cdot D=\rho, \\
\nabla \cdot B=0,
\end{gathered}
$$

where, $J$ is the source current density generated by the current intensity $I$ of the induction coil. $H$ is the magnetic field strength, $E$ is the electric field strength, $D$ and $B$ are the electric flux density and the 
magnetic flux density, respectively. $\mu_{M F C}$ is the magnetic permeability of the heated material, $\rho$ is the charge density.

Through the further derivation, the electro-magnetic equations in the isotropic dielectric material in this planar moving induction heating are governed by the Equations (5) and $(6)[2,10]$.

$$
\begin{aligned}
& \nabla^{2} A-\mu \varepsilon \frac{\partial^{2} A}{\partial t^{2}}=-\mu J \\
& \nabla^{2} \varphi-\mu \varepsilon \frac{\partial^{2} \varphi}{\partial t^{2}}=-\frac{\rho}{\varepsilon}
\end{aligned}
$$

where, $A$ is the magnetic vector potential and $\varphi$ is the electric scalar potential, which are related with the magnetic flux density $B(B=\nabla \times A)$ and the electrical field strength $E\left(E=-\nabla \phi-\frac{\partial A}{\partial t}\right) . \mu$ is the relative permeability and $\varepsilon$ is the relative dielectric of the heated material.

The heat source power induced in the surface of the workpiece $P_{L}$ can be calculated from the Equation (7) [2].

$$
P_{L}=q_{V} \cdot V=\frac{i^{2}}{\sigma} V=\frac{1}{2} \omega^{2} \sigma A^{2} V,
$$

where, $\sigma$ is the electrical conductivity of the heated material, $\omega$ is the angular frequency of the current of the induction coil related with the $f . V$ is the volume of the computational field.

The uniform heating source is usually defined as a rectangle shape, and the heat source flux density at the point $(x, y, z)$ is given by the Equation (8) [20]. $P_{L}$ is the induced eddy power in the surface of the workpiece and can be calculated by Equation (7).

$$
\dot{q}(x, y, z)=\frac{P_{L}}{4 a_{h} b_{h} c_{h}},
$$

where, $a_{h}, b_{h}, c_{h}$ are the length along the axis $x, y, z$, respectively.

The transient temperature increase $d T_{t^{\prime}}$ at the time $t$, and the heat source flux density at time $t^{\prime}$ can be calculated by Equation (9) [20].

$$
\begin{gathered}
d T_{t^{\prime}}=\frac{\dot{q} d t^{\prime}}{\rho c\left(4 \pi \kappa\left(t-t^{\prime}\right)\right)^{\frac{3}{2}}} \times \exp \left(-\frac{\left(x-x^{\prime}\right)^{2}+\left(y-y^{\prime}\right)^{2}+\left(z-z^{\prime}\right)^{2}}{4 \kappa\left(t-t^{\prime}\right)}\right) \\
=\int_{-a_{h}}^{a_{h}} \int_{-b_{h}}^{b_{h}} \int_{-c_{h}}^{c_{h}} \frac{P_{L}}{4 a_{h} b_{h} c_{h}} \cdot \frac{d t^{\prime}}{\rho c\left(4 \pi \kappa\left(t-t^{\prime}\right)\right)^{\frac{3}{2}}} \times \exp \left(-\frac{\left(x-x^{\prime}\right)^{2}+\left(y-y^{\prime}\right)^{2}+\left(z-z^{\prime}\right)^{2}}{4 \kappa\left(t-t^{\prime}\right)}\right) d z^{\prime} d y^{\prime} d x^{\prime}
\end{gathered}
$$

Where, $\rho$ is the density and $c$ is the capacity of the heated material. $\kappa$ is the thermal diffusivity, $\kappa=\lambda / \rho c, \lambda$ is the conductivity.

In Equation (9), the integrals can be derived as follows:

$$
\begin{gathered}
\int_{-a_{h}}^{a_{h}} \exp \left(-\frac{\left(x-x^{\prime}\right)^{2}}{4 \kappa\left(t-t^{\prime}\right)}\right) d x^{\prime} \\
=-\frac{\sqrt{4 \kappa \pi\left(t-t^{\prime}\right)}}{2}\left(\operatorname{Erf}\left(\frac{x-a_{h}}{\sqrt{4 \kappa\left(t-t^{\prime}\right)}}\right)-\operatorname{Erf}\left(\frac{x+a_{h}}{\sqrt{4 \kappa\left(t-t^{\prime}\right)}}\right)\right),
\end{gathered}
$$

where, the function $\operatorname{Erf}(x)$ is error function defined as follow [21]:

$$
\operatorname{Erf}(x)=\frac{2}{\sqrt{\pi}} \int_{0}^{x} e^{-\tau^{2}} d \xi
$$

The function $\operatorname{Erfh}(x)$ is defined as equation (12) [20].

$$
\operatorname{Erfh}\left(x, a_{h}, t^{\prime}\right)=\operatorname{Erfh}\left(\frac{x}{a_{h}}, F o_{s}\right)=\left(\operatorname{Erf}\left(\frac{x-a_{h}}{\sqrt{4 \kappa\left(t-t^{\prime}\right)}}\right)-\operatorname{Erf}\left(\frac{x+a_{h}}{\sqrt{4 \kappa\left(t-t^{\prime}\right)}}\right)\right)
$$


where, $F o_{s}$ is the Fourier number which is related with the length $a_{h}$ and the time $t-t^{\prime}$.

By substituting the Equations (10)-(12) in Equation (9), the final temperature formula can be derived as follow:

$$
\begin{gathered}
d T_{t^{\prime}}=T-T_{0} \\
=-\frac{P_{L}}{2^{5} \rho c a_{h} b_{h} c_{h}} \int_{0}^{t} \operatorname{Erfh}\left(x+v\left(t-t^{\prime}\right), a_{h}, t^{\prime}\right) \\
\times \operatorname{Erfh}\left(y, b_{h}, t^{\prime}\right) \operatorname{Erfh}\left(z, c_{h}, t^{\prime}\right) d t^{\prime} \\
=-\frac{1^{\prime}}{2^{5} \eta} \int_{0}^{t} \operatorname{Erfh}\left(\frac{x+v\left(t-t^{\prime}\right)}{a_{h}}, F o_{a_{h}}\right) \operatorname{Erfh}\left(\frac{y}{b_{h}}, F o_{b_{h}}\right) \operatorname{Erfh}\left(\frac{z}{c_{h}}, F o_{c_{h}}\right) \frac{d t^{\prime}}{t},
\end{gathered}
$$

where, $v$ is the moving velocity of the heated material, $\eta$ is the heating efficiency and is defined as [20]:

$$
\eta=\frac{\rho c a_{h} b_{h} c_{h}\left(T_{m}-T_{0}\right)}{P_{L} t}
$$

where, $T_{0}$ is the ambient temperature, $T_{m}$ is the melt temperature of the heated material Inconel 718.

\subsection{Finite Element Model}

In former research works, the numerical analysis of the stationary [10] and the moving [15] induction heating process is respectively conducted. The distribution of the coupled electric-magnetic field variables and the generation of the eddy power density are calculated by the finite element methods. The induction coils are made of a rectangular copper tube with low electrical resistivity and designed as planar shapes with the section of a hollow rectangle, as shown in Figure 3. The magnetic flux concentrator (MFC) is machined with the same groove shape as the coil and cover it for gathering the magnetic flux into the surface of the workpiece and improve the heating efficiency $[10,15]$. Figure 4 is the schematic system of the planar moving induction heating. Figure 5 is the corresponding finite element simulation model. The surrounding air and the compressed air is also magnetic computation field. Due to the large temperature gradient in the calculation, the surface and the sub-surface field in the workpiece should be meshed more finer, in which the structured grids with $0.1 \mathrm{~mm}$ thickness are adopted and there are 15 rectangle elements within $3 \mathrm{~mm}$ depth below the surface.

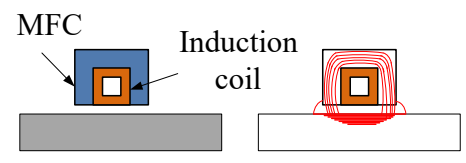

Figure 3. Section of the Induction coil and magnetic flux concentrator (MFC).

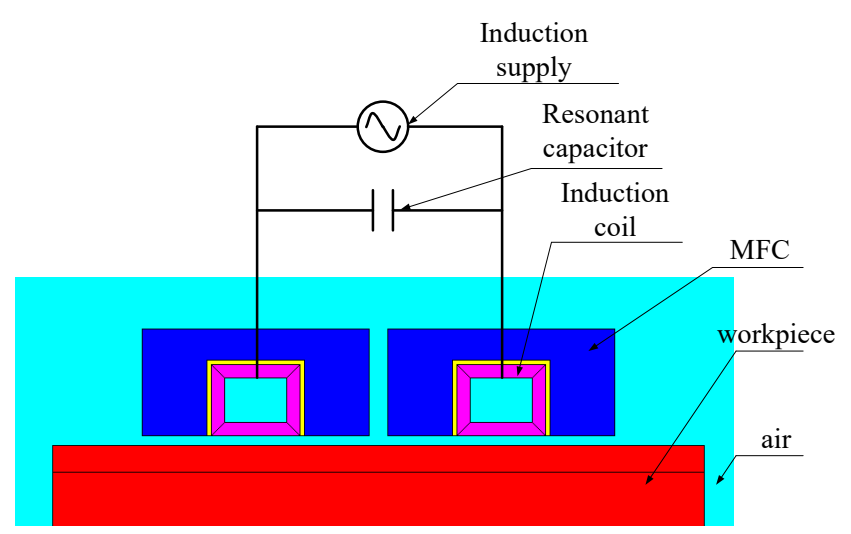

Figure 4. Schematic system of the planar moving induction heating. 


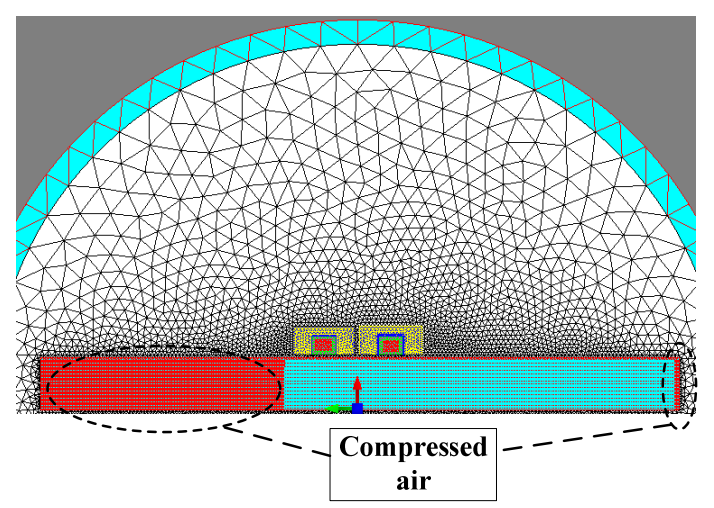

Figure 5. Finite element simulation model of the planar induction heating with magnetic flux concentrator (MFC).

\subsection{Material Parameters of the Heated Material}

The heated material in this work is Nickel-based super-alloy Inconel 718, which is machined into square blocks with smooth surfaces Ra $3.2 \mu \mathrm{m}$ and the residual stress relief is conducted.

The magnetic permeability of Inconel 718 is linearly and approximately equal to 1 when the heating temperature is below its Curie temperature. Figures $6-8$ show the measured resistivity, specific heat capacity and thermal conductivity as a function of temperature for the material being heated. It can be seen that the conductivity and the specific heat of the heated material are nearly linear, while the electrical resistivity has a nonlinearity change with temperature. In addition, the convective heat transfer coefficient in the surface is set as $\alpha=20 \mathrm{~W} /\left(\mathrm{m}^{2} \cdot \mathrm{K}\right)$ [22]. The radiation coefficient in the surface is set as $C_{s}=0.5 \mathrm{~W} /\left(\mathrm{m}^{2} \cdot \mathrm{K}^{4}\right)[10]$.

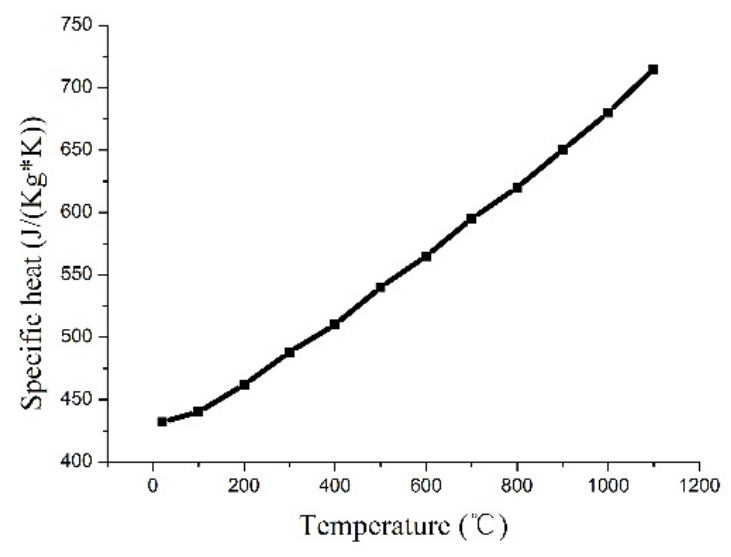

Figure 6. Conductivity of Inconel 718.

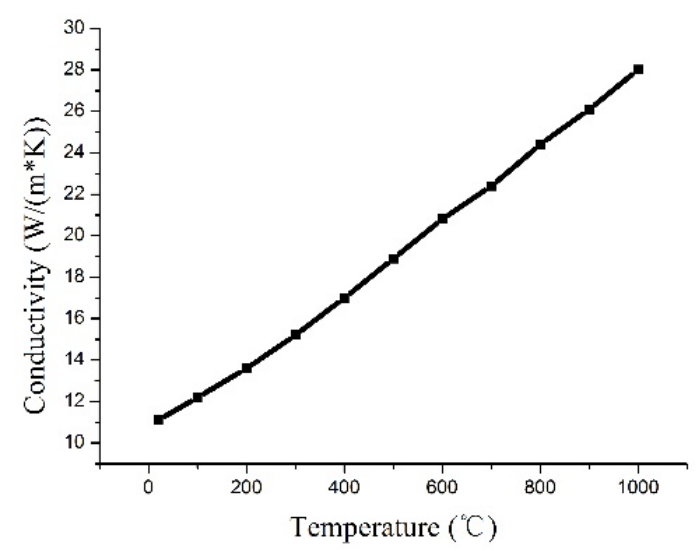

Figure 7. Specific heat of Inconel 718. 


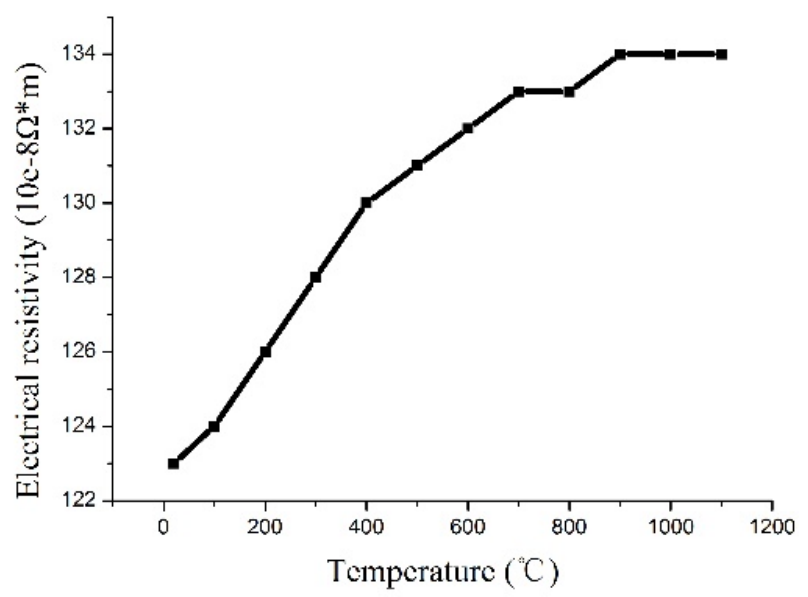

Figure 8. Electrical resistivity of Inconel 718.

\subsection{Experimental Measurement}

The planar moving induction heating experimental platform is established, as shown in Figure 9. The workpiece Inconel 718 is fixed on a moving platform apparatus and the velocity can be precisely controlled. The experimental system mainly includes induction heating power supply, frequency conversion voltage regulator, strengthening sensor (including concentrator MPB-MFC) and cooling device. The cooling device can circulate water inside the coil to prevent overheating of the coil and reduce energy consumption during heating. The validation experimental parameters are presented in Table 1, which mainly contains the MFC model, heating distance $d$, current intensity $I$, current frequency $f$ and the moving velocity $v$. The heating distance $d$ is set as $1 \mathrm{~mm}$ because the distance between the induction coil and the workpiece should be no more than $2 \mathrm{~mm}$ in order to concentrate the magnetic flux more efficiently. The frequency conversion regulator can realize the frequency regulation range from $10 \mathrm{kHz}$ to $50 \mathrm{kHz}$, and the intensity of the induction coil current is controlled from 0 to 1200 A. The levels of $I$ and $f$ are listed in Table 1 according to the former induction heating experimental analysis $[10,15]$. As to the velocity of the workpiece, it is verified that the velocity should be controlled at a low level, due to its negative effect on the induction heating [10].

In addition, the experimental system includes a temperature acquisition and analysis device. The surface temperature of the workpiece is obtained by infrared thermal imager (NEC R300W2-NNU). At the same time, the temperature history of the workpiece surface and internal points is measured by the semi-natural artificial thermocouple, as shown in Figure 9. By simultaneously measuring the surface temperature with a thermocouple and an infrared camera, the thermal imager can be calibrated, and the accuracy of the temperature measurement can be improved.

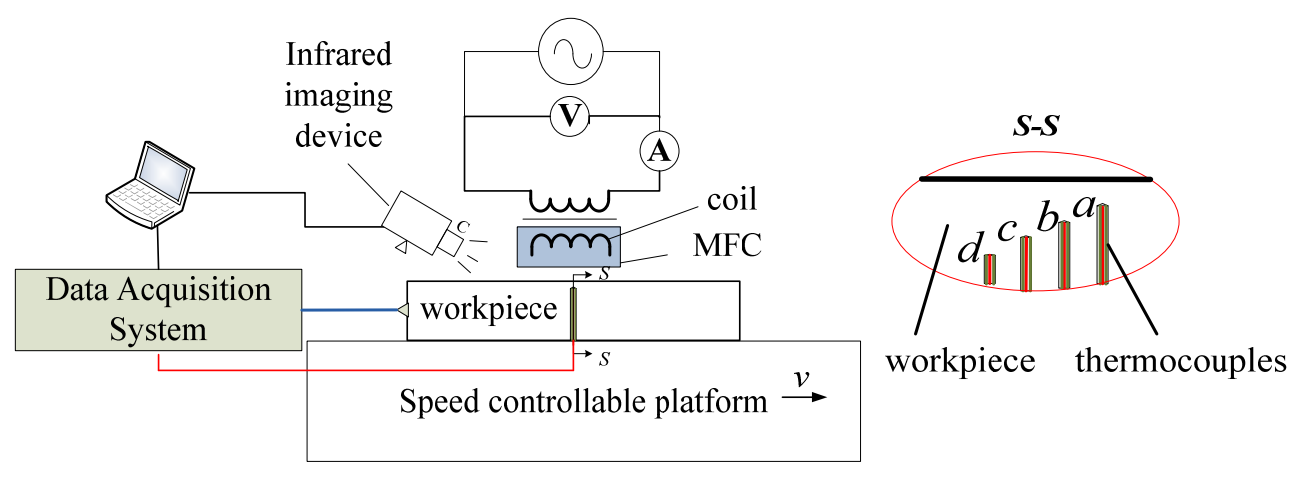

Figure 9. Experiment apparatus of the planar moving induction heating. 
Table 1. Experimental parameters of the planar moving induction heating.

\begin{tabular}{cc}
\hline Parameters & Value \\
\hline MFC model & Fluxtrol A \\
Heating Distance $d / \mathrm{mm}$ & 1 \\
$I / \mathrm{A}$ & $430,485,767,890$ \\
$f / \mathrm{kHz}^{-1}$ & $26.7,37.6$ \\
$\mathrm{v} / \mathrm{mms}^{-1}$ & $3,5,8,10$ \\
\hline
\end{tabular}

\section{Results and Discussion}

The power density profile in the surface during the planar stationary induction heating process is shown in Figure 10 while the input coil parameters are set as $I=430 \mathrm{~A}, f=37.6 \mathrm{kHz}$ [10]. Figures 11 and 12 are the power density evolutions with the various current intensity and current frequency, respectively. It is obvious and verified that the power density in the workpiece extremely depends on the current intensity and the frequency. Then the moving velocity is applied in the simulation model, the workpiece will be heated continuously.

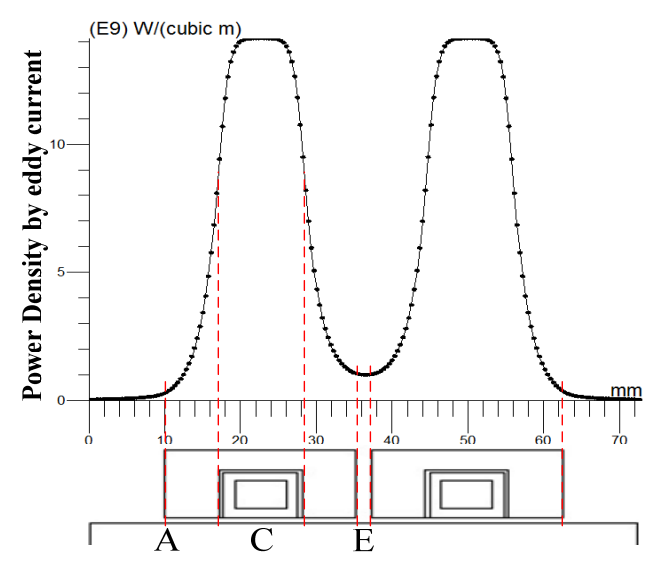

Figure 10. Power density profile in the surface of the heated workpiece ( $\mathrm{I}=430 \mathrm{~A}, \mathrm{f}=37.6 \mathrm{kHz})$ [8].

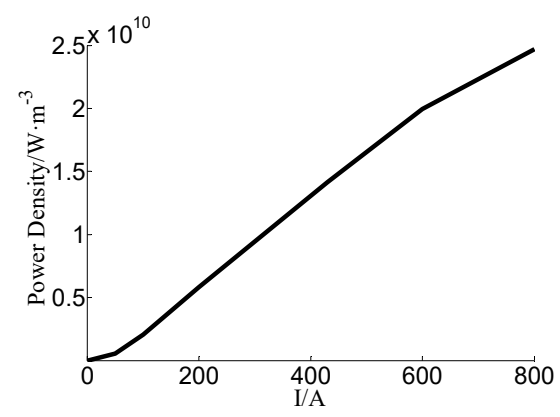

Figure 11. Power density variation with current intensity $I$.

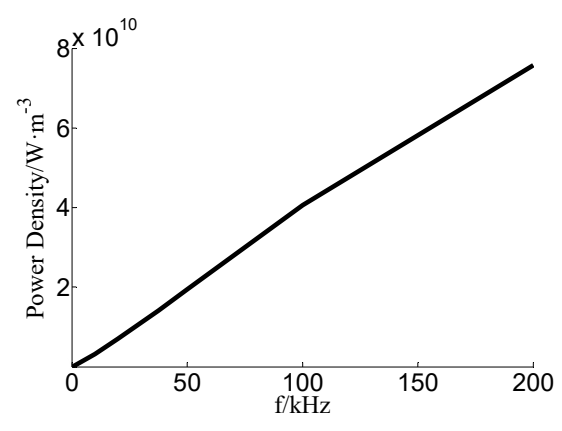

Figure 12. Power density variation with current frequency $f$. 
The power density then is extracted and used to calculate the final temperature distribution. Figure 13 presents the temperature profile obtained from the analytical model in this paper, in which the input parameters are respectively set as $I=430 \mathrm{~A}, f=37.6 \mathrm{kHz}, v=5 \mathrm{~mm} / \mathrm{s}$. Under these input parameters, the power density in the surface is $14 \mathrm{e} 10 \mathrm{~W} / \mathrm{m}^{3}$ and the corresponding power applied into the analytical model is $70 \mathrm{~W}$. Figure 14 is the temperature profile calculated by the finite element simulation model. It is shown that in the analytical calculation the most of heat is concentrated on the surface of the workpiece and the maximum temperature is in the surface, due to the skin effect in the induction heating, which is similar with the finite element simulation result. The temperature is mainly distributed in the surface and sub-surface region of the workpiece, due to the skin effect in the induction heating process, which is commonly realized and validated $[2,10]$. In order to verify the analytical computational results, several finite element simulations and the corresponding validation experiments are conducted under various input parameters of the planar moving induction heating process. The experimental parameters and the corresponding results are listed in Table 2. Figure 15 shows the maximum temperature in the workpiece while the velocity is $5 \mathrm{~mm} / \mathrm{s}$, while Figure 16 shows the Maximum temperature in the workpiece while the velocity is $8 \mathrm{~mm} / \mathrm{s}$. Figure 17 shows the Maximum temperature in the workpiece at four different velocity levels. It is observed that the maximum temperature by analytical calculation is higher than the simulation results and the experimental results. The main reason causing this situation is that the simulation model has taken into consideration of the surface heat transfer effect while the analytical model ignores it, which varies with the temperature $[10,22]$. Moreover, the experimental data has a measurement error, due to the emissivity parameter of the infrared thermal imager, which is only set as a constant and in fact varies with the temperature.

In addition, it is investigated that the higher input current intensity $I$ of the coil, the higher temperature is acquired (Test 1 vs. Test 3, Test 2 vs. Test 4 ), which has a good agreement with the finite element simulation results and the experiment results [10]. Similarly, the heated temperature rises as the frequency $f$ increases at the same level as the current intensity $I$ (Test 1 vs. Test 2, Test 3 vs. Test 4). The same conclusion can be drawn when the moving velocity becomes $8 \mathrm{~mm} / \mathrm{s}$, as shown in Figure 17. By compared with Figures 15 and 16, it is found that temperature obtained will experience a drop while the moving velocity changes from $5 \mathrm{~mm} / \mathrm{s}$ to $8 \mathrm{~mm} / \mathrm{s}$. It is proved in Figure 17 that the moving velocity also plays a vital rule in the temperature control in the planar induction heating process, besides the current intensity $I$ and the current frequency $f$ [15].

The relative errors of the analytical calculation and the finite element simulation are listed in Table 2. It is clear shown that the relative errors between the analytical maximum temperature and the corresponding experimental data are lower than $25 \%$, especially there is a low error level when the temperature is higher than $200{ }^{\circ} \mathrm{C}$. This result is matched with the fact that the convective heat transfer coefficient decreases with the temperature rises in reality and the difference in the analytical model will drop when the heated temperature rises than $200{ }^{\circ} \mathrm{C}$ [22]. It is also true in Table 2 that the finite element simulation possesses a lower relative error than the analytical calculation in this work. However, the computation efficiency of the analytical model is much higher than the finite element simulation model. The calculation time of the analytical model in this work just needs several seconds while the finite element simulation model requires much more time, which is verified in other applications [17]. Thus considering the indispensable simplification during the analytical modeling and the difficult precise calculation and control of the induction coil during the planar moving induction experiment system, it is believable that the relative errors of these validation experiments listed in Table 2 are considered to be in an acceptable level. Thus it is believed that the established analytical model in this work can be used to predict the temperature evolution in the heated workpiece by the planar moving induction heating. Moreover, in order to obtain more accurate results, the next research work needs to consider the heat exchange coefficient in the analytical modeling. 


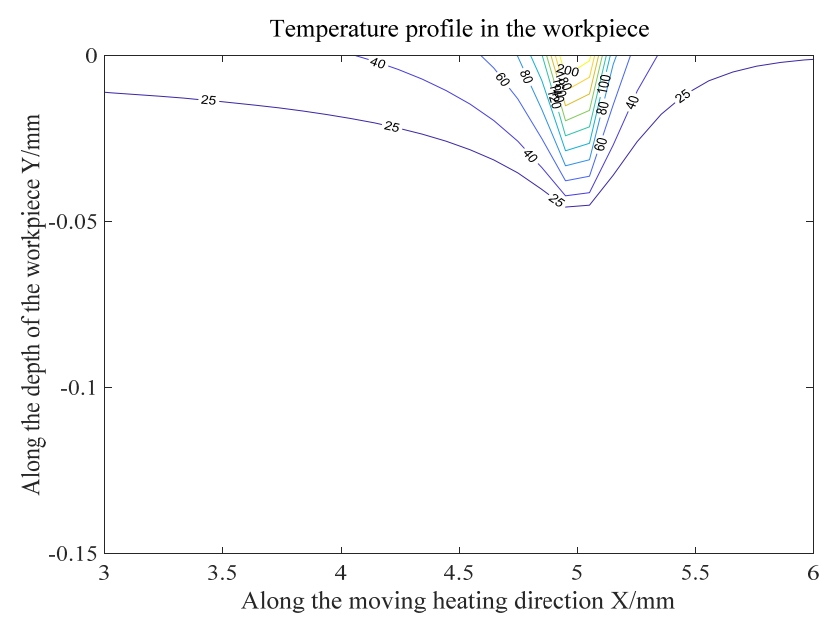

Figure 13. Temperature profile calculated by the analytical method.
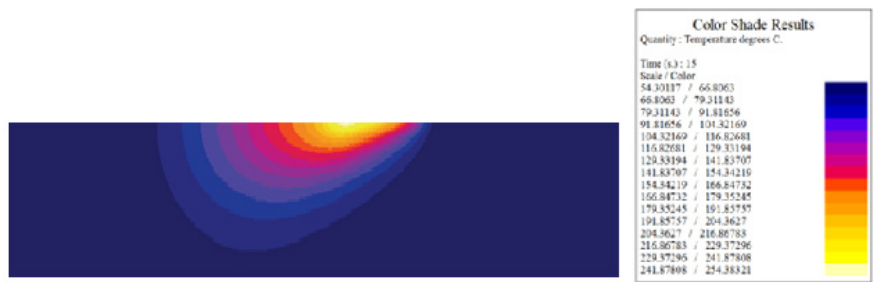

Figure 14. Temperature profile calculated by finite element simulation.

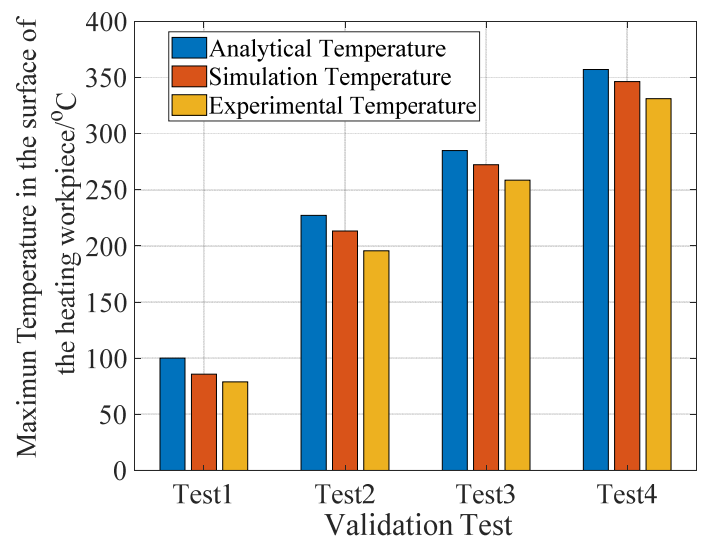

Figure 15. Maximum temperature validation in the surface of the workpiece $(v=5 \mathrm{~mm} / \mathrm{s})$.

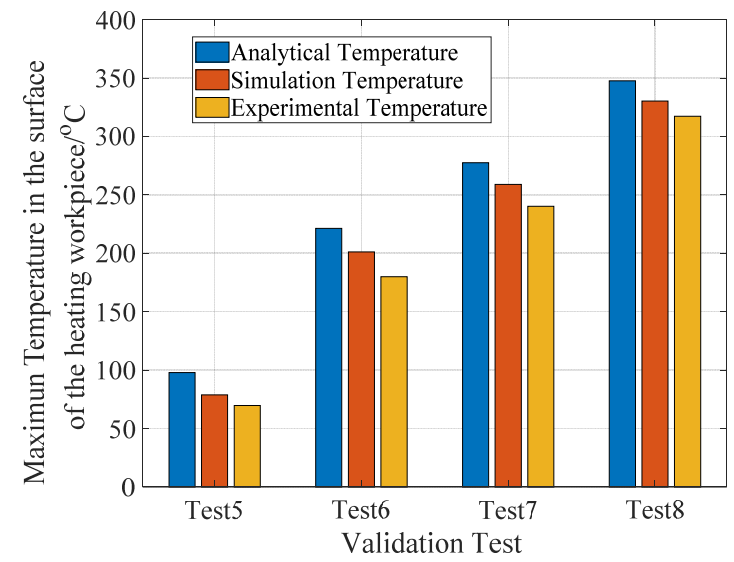

Figure 16. Maximum temperature validation in the surface of the workpiece $(v=8 \mathrm{~mm} / \mathrm{s})$. 


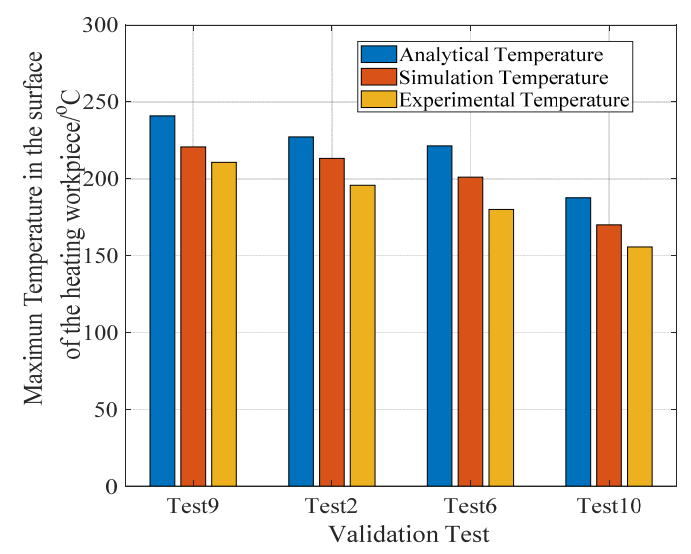

Figure 17. Maximum temperature validation in the surface of the workpiece $(I=430 \mathrm{~A}, f=37.6 \mathrm{kHz}$, Test 9: $v=3 \mathrm{~mm} / \mathrm{s}$; Test 2: $v=5 \mathrm{~mm} / \mathrm{s}$; Test 6: $v=8 \mathrm{~mm} / \mathrm{s}$; Test 10: $v=10 \mathrm{~mm} / \mathrm{s}$ ).

Table 2. Maximum temperature and the relative errors with experimental results.

\begin{tabular}{|c|c|c|c|c|c|c|c|c|}
\hline Test & I/A & $f / \mathbf{k H z}$ & $\begin{array}{l}\text { Velocity/ } \\
\text { mms }^{-1}\end{array}$ & $\begin{array}{c}\text { Analytical } \\
\text { Predicted } /{ }^{\circ} \mathrm{C}\end{array}$ & $\begin{array}{c}\mathrm{FE} \\
\text { Simulation } /{ }^{\circ} \mathrm{C}\end{array}$ & $\begin{array}{c}\text { Experimental } \\
\text { Results } /{ }^{\circ} \mathrm{C}\end{array}$ & $\begin{array}{l}\text { FE Simulation } \\
\text { Error/\% }\end{array}$ & $\begin{array}{c}\text { Analytical } \\
\text { Error } / \%\end{array}$ \\
\hline 1 & 485 & 26.7 & 5 & 100.10 & 85.79 & 80.91 & 6.53 & 23.7 \\
\hline 2 & 430 & 37.6 & 5 & 227.20 & 213.28 & 195.7 & 8.98 & 16.1 \\
\hline 3 & 767 & 26.7 & 5 & 284.97 & 272.32 & 258.54 & 5.33 & 10.2 \\
\hline 4 & 890 & 37.6 & 5 & 357.18 & 346.43 & 331.27 & 4.58 & 7.82 \\
\hline 5 & 485 & 26.7 & 8 & 97.94 & 78.92 & 73.72 & 7.06 & 24.7 \\
\hline 6 & 430 & 37.6 & 8 & 221.39 & 201.08 & 189.96 & 5.85 & 16.5 \\
\hline 7 & 767 & 26.7 & 8 & 277.50 & 258.98 & 240.22 & 7.81 & 15.5 \\
\hline 8 & 890 & 37.6 & 8 & 347.64 & 330.34 & 317.23 & 4.13 & 9.59 \\
\hline 9 & 430 & 37.6 & 3 & 240.93 & 220.62 & 210.71 & 4.7 & 14.3 \\
\hline 10 & 430 & 37.6 & 10 & 187.65 & 169.98 & 155.57 & 9.26 & 20.6 \\
\hline
\end{tabular}

\section{Conclusions}

This paper introduces an analytical model to predict the temperature profile in a planar moving induction heating process. The power density of induced eddy current $\mathrm{q}_{\mathrm{v}}$ in the heated workpiece can be obtained based on Maxwell equations, which govern the general induction heating. Then the transient temperature evolution will be calculated using the mathematical equations defined as a rectangle moving heating source with the uniform power $\mathrm{P}_{\mathrm{L}}$. In addition, several finite element simulations and experiments are conducted to validate the analytical calculation model, and the following conclusions can be achieved:

(1) The temperature profile calculated by the analytical model introduced in this work is similar to the finite element simulation results. By comparing with finite element simulation and the corresponding validation experiments, the maximum temperature in the workpiece is verified while the velocity is $5 \mathrm{~mm} / \mathrm{s}$ and $8 \mathrm{~mm} / \mathrm{s}$, respectively. It is noticed that the maximum temperature by analytical calculation is higher than the simulation results and the experimental results, due to the fact that the simulation model has taken into consideration of the surface heat transfer effect while the analytical model ignores it. It is presented that the relative errors between the analytical maximum temperature and the corresponding experimental data are lower than $25 \%$, and there is a low error level when the temperature is higher than 200, which is matched with the fact that the convective heat transfer coefficient decreases with the temperature rises in reality.

(2) The higher input current intensity I of the coil, the higher temperature is acquired, which has a good agreement with the finite element simulation results and the experiment results. Similarly, the heated temperature rises as the frequency $f$ increases at the same level of $I$. It is also proved that the moving velocity $v$ influences the temperature in the planar induction heating process, thus it is essentially to treat $v$ as an important parameter in the temperature precisely prediction. 
(3) The computation efficiency of the analytical model in this work is higher than the finite element simulation model. Taking into consideration of the indispensable simplification during the analytical modeling and the difficulties in precisely calculation and controlling of the induction coil during the planar moving induction experiment system, it is believed that the established analytical model in this work can be used to predict the temperature evolution in the heated workpiece by the planar moving induction heating. In addition, in order to acquire more precise temperature prediction, it is essential that the convection heat transfer should be considered in the following research work, especially in the lower heated temperature level.

Author Contributions: The methodology, F.L.; validation, F.L. and J.N.; data curation, F.L.; writing-original draft preparation, F.L.; writing — review and editing, J.N. and S.Y.L.; funding acquisition, F.L.

Funding: This research was funded by the National Science Foundation of China (No.: U1430116), the Foundation of China's National Scholarship Council (No.: 201806935026), Shanxi Provincial Science and Technology Major Project of China (No.: 20181101008) and Natural Science Foundation of Shanxi Province, China (No.: 201701D121078).

Conflicts of Interest: The authors declare no conflict of interest.

\section{References}

1. Tomita, H. Industry applications of small induction heater. In Proceedings of the 2012 9th France-Japan and 7th Europe-Asia Congress on and Research and Education in Mechatronics, Paris, France, 21-23 November 2012.

2. Rudnev, V.; Loveless, D.; Cook, R.L. Handbook of Induction Heating, 2nd ed.; CRC Press: Boca Raton, FL, USA, 2017.

3. Beate, O.T. Induction thermography for surface crack detection and depth determination. Appl. Sci. 2018, 8, 257. [CrossRef]

4. Zhou, C.; Liu, X.; Apostolidis, P.; Scarpas, A.T.; He, L. Induction heating-assisted compaction in Porous Asphalt Pavements: A computational study. Appl. Sci. 2018, 8, 2308. [CrossRef]

5. Kilic, V.T.; Unal, E.; Demir, H.V. Coupling and power transfer efficiency enhancement of modular and array of planar coils using in-plane ring-shaped inner ferrites for inductive heating applications. J. Appl. Phys. 2017, 122, 83-89. [CrossRef]

6. Bui, H.T.; Hwang, S.J. Design of an induction heating coil coupled with magnetic flux concentrators for barrel heating of an injection molding machine. Proc. Inst. Mech. Eng. C J. Mech. Eng. Sci. 2014, 229, 518-527. [CrossRef]

7. Ruffini, R.S.; Ruffini, R.T.; Nemkov, V.S.; Goldstein, R.C. Advanced Design of Induction Processes and Work Coils for Heat Treating and Assembly in Automotive Industry. In Proceedings of the 1999 SAE Southern Automotive Manufacturing Conference and Exposition, Birmingham, AL, USA, 28-30 September 1999.

8. Nemkov, V.; Goldstein, R.; Ruffini, R. Magnetic Flux Controllers for Induction Heating Applications. 2004, Volume 25, pp.567-572. Available online: https://www.researchgate.net/publication/294644619_Magnetic_ flux_controllers_for_induction_heating_applications (accessed on 6 April 2019).

9. Kagimoto, H.; Miyagi, D.; Takahashi, N.; Uchida, N.; Kawanaka, K. Effect of Temperature Dependence of Magnetic Properties on Heating Charac-teristics of Induction Heater. IEEE Trans. Magn. 2010, 46, 3018-3021. [CrossRef]

10. Li, F.; Li, X.K.; Qin, X.F.; Rong, Y.M. Study on the plane induction heating process strengthened by magnetic flux concentrator based on response surface methodology. J. Mech. Sci. Technol. 2018, 32, 2347-2356. [CrossRef]

11. Barka, N. Study of the machine parameters effects on the case depths of 4340 spur gear heated by induction-2D model. Int. J. Adv. Manuf. Technol. 2017, 93, 1173-1181. [CrossRef]

12. Luozzo, N.D.; Fontana, M.; Arcondo, B. Modelling of induction heating of carbon steel tubes: Mathematical analysis, numerical simulation and validation. J. Alloys Compd. 2012, 536, 564-568. [CrossRef]

13. Choi, J.K.; Park, K.S.; Lee, S.S. Prediction of high-frequency induction hardening depth of an AISI 1045speciman by finite element analysis and experiments. Int. J. Precis. Eng. Manuf. 2018, 19, 1821-1827. [CrossRef] 
14. Khazaal, M.H.; Abdulbaqi, I.M.; Thejel, R.H. Modeling, design and analysis of an induction heating coil for brazing process uning FEM. In Proceedings of the 2016 Al-Sadey International Conference on Multidisciplinary in IT and Communication Science and Applications, Baghdad, Iraq, 9-10 May 2016.

15. Li, F.; Li, X.K.; Zhu, T.X.; Rong, Y.M. Numerical simulation of the moving induction heating process with magnetic flux concentrator. Adv. Mech. Eng. 2013, 5. [CrossRef]

16. Ning, J.; Liang, S.Y. Prediction of temperature distribution in orthogonal machining based on the mechanics of the cutting process using a constitutive model. J. Manuf. Mater. Process. 2018, 37, 37. [CrossRef]

17. Ning, J.; Liang, S.Y. Analytical modeling of machining forces of ultra-fine-grained titanium. Int. J. Adv. Manuf. Technol. 2019, 101, 627-636. [CrossRef]

18. Jankowski, T.A.; Pawley, N.H.; Gonzales, L.M.; Ross, C.A. Approximate analytical solution for induction heating of a solid cylinders. Appl. Math. Model. 2016, 40, 2770-2782. [CrossRef]

19. Streblau, M. Mathematical model of induction heating processs in axial symmetric inductor-detail systems. TEM J. 2014, 3, 162-166.

20. Elsen, M.V.; Baelmans, M.; Mercelis, P.; Kruth, J.P. Solutions for modelling moving heat sources in a semi-infinite medium and applications to laser material processing. Int. J. Heat Mass Transf. 2007, 50, 4872-4882. [CrossRef]

21. Carslaw, H.; Jaeger, J. Conduction of Heat in Solids, 2nd ed.; Clarendon Press: Oxford, UK, 1959.

22. Zgraja, J.; Teodorczyk, T. Estimation of convection coefficient of induction heated cylindrical charge. Przeglad Elektrotechnicczny 2010, 86, 328-329.

(C) 2019 by the authors. Licensee MDPI, Basel, Switzerland. This article is an open access article distributed under the terms and conditions of the Creative Commons Attribution (CC BY) license (http:/ / creativecommons.org/licenses/by/4.0/). 